\title{
Adherent-invasive Escherichia coli (AIEC) in pediatric Crohn's disease patients: phenotypic and genetic pathogenic features
}

Maria Pia Conte ${ }^{1 *}$, Catia Longhi ${ }^{1}$, Massimiliano Marazzato ${ }^{1}$, Antonietta Lucia Conte ${ }^{1}$, Marta Aleandri ${ }^{1}$, Maria Stefania Lepanto ${ }^{1}$, Carlo Zagaglia ${ }^{1}$, Mauro Nicoletti ${ }^{2}$, Marina Aloi ${ }^{3}$, Valentina Totino ${ }^{1}$, Anna Teresa Palamara ${ }^{4,5}$ and Serena Schippa ${ }^{1}$

\begin{abstract}
Background: Adherent-invasive Escherichia coli (AIEC) have been implicated in the ethiopathogenesis of Crohn's disease (CD). In this study, we analyzed a collection of intestinal mucosa-associated E. coli isolates, presenting AIEC phenotypes, isolated from biopsies of CD pediatric patients and non-inflammatory bowel diseases (IBD) controls, in order to investigate their genetic and phenotypic pathogenic features.

Results: A total of 616 E. coli isolates from biopsies of four pediatric CD patients and of four non-IBD controls were collected and individually analyzed. For AIEC identification, adherent isolates were assayed for invasiveness, and the capacity of the adhesive-invasive isolates to survive and replicate intracellularly was determined over macrophages J774. In this way we identified 36 AIEC-like isolates. Interestingly, their relative abundance was significantly higher in CD patients $(10 \% ; 31 / 308)$ than in non-IBD controls $(1 \% ; 5 / 308)(X 2=38.96 p<0.001)$. Furthermore pulsed field gel electrophoresis (PFGE) and randomly amplified polymorphic DNA (RAPD) techniques were applied to analyze the clonality of the 36 AlEC-like isolates. The results obtained allowed us to identify 27 distinct genotypes (22 from CD patients and 5 from non-IBD controls). As for the AIEC prototype strain LF82, all 27 AlEC genotypes presented an aggregative pattern of adherence (AA) that was inhibited by D-mannose, indicating that adhesiveness of AIEC is likely mediated by type 1 pili. PCR analisys was used to investigate presence of virulence genes. The results indicated that among the $27 \mathrm{AlEC}$ isolates, the incidence of genes encoding virulence factors K1 $(X 2=6.167 P=0.013)$, $\mathrm{kpsMT}$ ॥ $(X 2=6.167 P=0.013)$, fyuA $(X 2=6.167 P=0.013)$, and ibeA $(X 2=8.867 P=0.003)$ was significantly higher among AIEC strains isolated from $C D$ patients than non-IBD controls.

Conclusions: The identification of AIEC strains in both CD and non-IBD controls, confirmed the "pathobiont" nature of AIEC strains. The finding that AIEC-like isolates were more abundant in CD patients, indicates that a close association of these strains with CD may also exists in pediatric patients.
\end{abstract}

Keywords: Gut microbiota, Pathobionts, Crohn's disease, Adherent-invasive E. coli, AIEC

\footnotetext{
*Correspondence: mariapia.conte@uniroma1.it

'Department of Public Health and Infectious Diseases, 'Sapienza' University of Rome, Rome, Italy

Full list of author information is available at the end of the article
}

\section{Biomed Central}

(c) 2014 Conte et al.; licensee BioMed Central Ltd. This is an Open Access article distributed under the terms of the Creative Commons Attribution License (http://creativecommons.org/licenses/by/4.0), which permits unrestricted use, distribution, and reproduction in any medium, provided the original work is properly credited. The Creative Commons Public Domain Dedication waiver (http://creativecommons.org/publicdomain/zero/1.0/) applies to the data made available in this article, unless otherwise stated. 


\section{Background}

Crohn's disease (CD) is a disorder of the human bowel, resulting from chronic inflammation of the gastrointestinal tract. Characteristics of CD are patchy inflammation, full-thickness lesions of the intestinal wall, and granulomas $[1,2]$. The etiology of this disease has not been fully elucidated yet although it is generally accepted that the chronic inflammation is due to deregulated immune responses towards the intestinal microbiota $[3,4]$. The intestinal microbiota is a dynamic ecosystem that has developed a mutualistic relationship with its host and plays a crucial role in the development and homeostasis of the immune system [5]. Recent studies have suggested that the intestinal microbiota composition contribute to $\mathrm{CD}$ pathogenesis since, compared to normal individuals, the microbiota of $\mathrm{CD}$ patients display reduced diversity and altered composition [6]. Unbalanced composition of the intestinal microbiota has been defined dysbiosis. A dysbiosis, localized or generalized, has been reported in CD patients and it has been hypothesized that the loss or reduction in the number of beneficial microbes may favor colonization by potentially aggressive pathogenic microorganisms [7,8]. Whether dysbiosis is a consequence, a cause or a factor contributing to the insurgence, development of the disease remains poorly understood. To date, Mycobacterium paratuberculosis and Escherichia coli strains have been proposed to be associated with the onset of CD [9]. In particular, increased number of mucosa associated $E$. coli are observed in $C D$ patients [10] and some genotypes, more than others, appear to be associated with the disease [11]. Among these, mucosa-associated E. coli strains, have acquired a particular relevance to their strong adhesiveinvasive properties, $[12,13]$. This phenotype, called E. coli AIEC (adherent/invasive E. coli), has been proposed as a separate pathogenetic category. Several studies conducted mainly with strains isolated from adult CD patients, have suggested that AIEC strains may be involved in the onset and/or in the persistence of CD [14-16]. A detailed study of the prototype of these strains, AIEC LF82 strain, has revealed that it is able to adhere and to invade enterocytes, and to survive and replicate within macrophages without causing host cell death [17]. The adhesion-invasion phenotype of LF82 strain requires the expression of type 1 pili, and of several outer membrane proteins (OMPs), [18-20]. Furthermore, it has been shown that LF82 was able to translocate the intestinal mucosa, thus altering its permeability [21] and to move into deeper tissues activating an inflammatory immune response [22]. LF82 was also shown to be able to escape autophagy both in intestinal epithelial and dendritic cells and to interact with the $M$ cells of Peyer's patches, through the expression of long polar fimbriae $[23,24]$. In silico analysis of the genome of LF82 strain indicates the presence of patho-adaptive mutations whose role in the pathogenicity of this strains have not been fully characterized yet [25]. Furthermore, it has been recently reported that transient colonization of TLR5-deficient mice with AIEC strains, is sufficient to induce intestinal inflammation and dysbiosis [26], reinforcing the hypothesis that AIEC strains likely play a central role in triggering chronic intestinal inflammation in susceptible host. Therefore, to precisely define the role of these bacteria in inflammatory bowel diseases (IBD) we need to deepen our knowledge regarding the virulence traits of these strains, especially for those isolated from pediatric $C D$ patients whose available information is still very limited. In this work we collected and characterized 616 mucosa associated $E$. coli isolates present in ileum biopsies from four CD and four non-IBD pediatric patients (77 E. coli isolates per ileal biopsy). The relative abundance of isolates presenting AIEC-like properties was determined. Moreover, genotypic richness and the presence of selected virulence genes of AIEC-like strains were characterized using different molecular approaches.

\section{Methods}

\section{Patients and bacterial strains}

Six hundred-sixteen mucosa-associated independent $E$. coli isolates were collected from ileum biopsies of four pediatric patients with active $C D$ and from four pediatric patients with functional intestinal disorders but presenting normal colonoscopy and histology (non-IBD controls) (age range 2-14 years). Patients were recruited at the Pediatric Gastroenterology Unit of the University "Sapienza" of Rome, Italy. The study protocol was approved by the Committee on Ethical Practice of the 'Policlinico Umberto I' hospital. Children were enrolled in the study after written informed consent from their parents. The diagnostic investigation was carried out according to widely agreed international protocols. Infectious and systemic diseases as well as structural abnormalities of the gastrointestinal tract were excluded in all patients. No patient had food allergy or malabsorption, and invasive organisms, parasites and ova were not found in the stools. Clostridium difficile or its toxins were not detected in the stool of patients included in the study. No patients had previous treatment with azathioprine/6mercaptopurine, ciclosporin or other immunosuppressive agents at any time before the enrolment. The four children with $C D$ showed an ileocolonic involvement, and had a disease activity score ranging to moderate to severe. All patients did not receive any antibiotic and corticosteroid treatments within 3 months and four weeks, respectively, before biopsies were taken. Isolation and characterization of independent $E$. coli isolates from biopsy tissues have been described previously [27]. Briefly, each biopsy sample was washed in $500 \mu \mathrm{l}$ of buffered physiological saline supplemented with 
$0.016 \%$ dithioerythritol to remove the mucus and then shacked four times for $30 \mathrm{~s}$ in fresh physiological saline. At this point the biopsy specimens were hypotonically lysed by wortexing for $30 \mathrm{~min}$ in $500 \mu \mathrm{l}$ of distilled water and $100 \mu \mathrm{l}$ of each lysed suspension was diluted and directly plated onto Mac Conkey plates to obtain well-isolated colonies. Biochemical identification of $E$. coli isolates was carried out with the API 20E system (bio-Merieux-Italia, Rome, Italy) and/or using the indole assay. Seventy-seven E. coli isolates per biopsy were subjected to further analysis $E$. coli $\mathrm{K}-12$ reference strain DH5 $\alpha$, E. coli EPEC 32 (O55), EIEC strain HN280 [28] and reference E. coli AIEC LF82 strain (a kind gift of Arlette Darfeuille-Michaud, Université d'Auvergne, France) were used as positive or negative controls in adhesioninvasion assays. AIEC strain LF82 and E. coli reference strains EAEC 042, ETEC EDL 1493, DAEC C1845 and ExPEC CFT073 (provided by Prof. P. Escobar-Paramo; INSERM, Paris, France) were used to compare genotypic and phenotypic characteristics of clinical isolates. Strains were usually grown in Brain Heart Infusion (BHI, Oxoid, Rome, Italy) or on Trypticase Soy Agar plates (TSA, Oxoid) overnight at $37^{\circ} \mathrm{C}$. Cultures were stocked at $-70^{\circ} \mathrm{C}$ in the presence of $15 \%$ glycerol.

\section{Cells}

Human Caco-2 (ATCC HTB-37) and HEp-2 (ATCC CCL-23) cell lines were used to determine bacterial adhesiveness and invasiveness of the $E$. coli isolates. HEp-2 cells were maintained in Eagle's minimal essential medium (E-MEM, Sigma, Italy) with 5\% heat-inactivated foetal calf serum (FCS, Euroclone Italy) supplemented with $1 \%$ penicillin/streptomycin, in $5 \% \mathrm{CO}_{2}$ atmosphere at $37^{\circ} \mathrm{C}$. Caco-2 cells were grown in Minimum Essential Medium (MEM, Euroclone, Milan, Italy), supplemented with $1 \%$ penicillin/streptomycin and 10\% FCS and maintained in $5 \% \mathrm{CO}_{2}$ atmosphere at $37^{\circ} \mathrm{C}$. The macrophage-like J774A.1 cell line (ATCC TIB-67) was used to determine survival and multiplication in macrophages. J774 macrophages were maintained in RPMI 1640 medium (Euroclone, Italy) supplemented with $10 \%$ FCS and $1 \%$ penicillin/streptomycin and $5 \% \mathrm{CO}_{2}$ at $37^{\circ} \mathrm{C}$.

\section{Adhesiveness}

All 616 E. coli isolates were individually tested for their ability to adhere to cultured cells. Briefly, HEp-2 cell monolayers were cultured on glass coverslips in 24-well plates at a density of $1 \times 10^{5}$ cells/well for $24 \mathrm{~h}$ at $37^{\circ} \mathrm{C}$. When needed the medium was replaced $3 \mathrm{~h}$ before infection with complete medium containing $0.5 \%$ (wt/vol) D-mannose (Sigma-Aldrich, Italy). Bacterial cultures were harvested in the exponential phase and suspended in culture medium with and without $0.5 \% \mathrm{D}$-mannose. Cell monolayers were infected with bacterial suspensions $\left(10^{6}\right.$ bacteria/ml; $\mathrm{MOI}=10$ ) and incubated at $37^{\circ} \mathrm{C}$ for $3 \mathrm{~h}$. At the end of incubation period infected monolayers were extensively washed with PBS, fixed in methanol, Giemsa stained and examined with a light microscope. The ratio between the number of adherent bacteria and the number of plated cells was determined counting manually adherent bacteria present in 10 to 20 randomly chosen microscopic fields. A strain was considered to be adherent if it was observed to adhere to more than $40 \%$ of cells. E. coli AIEC LF82 and E. coli K-12 DH5 $\alpha$ strains were utilized as positive and negative controls, respectively. Adhesion assays were performed in three independent experiments, in duplicate.

\section{Invasiveness}

The invasive ability of isolates was carried out only with strains presenting an adhesive phenotype. Invasiveness was determined using the gentamicin protection assay, as described by Darfeuille-Michaud et al. [13]. Adhesive strains were then used to individually infect monolayers of HEp-2 cells cultured in 24-well plates at a density of $2 \times$ $10^{5}$ cells/well. Bacteria were grown overnight in BHI broth at $37^{\circ} \mathrm{C}$, and HEp-2 cell monolayers were infected with $0.5 \mathrm{ml}$ of bacterial suspensions $\left(2 \times 10^{6} ; \mathrm{MOI}=10\right)$ and incubated for $3 \mathrm{~h}$ at $37^{\circ} \mathrm{C}$. At the end of incubation period, cell monolayers were washed four times with PBS and fresh medium with $100 \mu \mathrm{g} / \mathrm{ml}$ of gentamicin (Sigma) was added to each well and incubation was continued for $1 \mathrm{~h}$ to allow intra-cellular multiplication. Monolayers were extensively washed and lysed with a solution of $1 \% \mathrm{vol} / \mathrm{vol}$ Triton X-100. Dilutions of cell lysates were plated in TSA agar plates to determine the number of viable bacteria (invasive). An isolate was considered invasive when the ratio of the number of intracellular bacteria/initial inoculum X 100 was $\geq 0.1 \%$ (i.e. $\geq 2 \times 10^{3}$ bacteria/well).

\section{Survival and replication in $\mathbf{J 7 7 4}$ macrophages}

The macrophages cell line J774 was used as model to assess survival and intracellular multiplication of the adherent/invasive $E$. coli isolates as described by Bringer et al. [29] with minor modifications. Briefly macrophages were seeded in 24-well tissue culture plates at a density of $2 \times 10^{5}$ cells/well, grown for 24 hours at $37^{\circ} \mathrm{C}$ and infected with adherent/invasive $E$. coli isolates $(\mathrm{MOI}=10)$. After $20 \mathrm{~min}$ of incubation at $37^{\circ} \mathrm{C}$, infected monolayers were extensively washed with PBS, and supplemented with fresh culture medium containing $100 \mu \mathrm{g} / \mathrm{ml}$ of gentamicin for $40 \mathrm{~min}$ at $37^{\circ} \mathrm{C}(1 \mathrm{~h}$ post infection). One hour post infection, fresh medium containing $50 \mu \mathrm{g} / \mathrm{ml}$ of gentamicin was added and infected monolayers were further incubated for additional 24 hours. Survival and replication of bacteria within macrophages was determined 1 and $24 \mathrm{~h}$ post-infection as described above. 
Isolates were considered able to survive and multiply in macrophages when the ratio between the number of intracellular bacteria recovered after $24 \mathrm{~h}$ of incubation and those recovered after $1 \mathrm{~h}$ (X 100) was $\geq 100 \%$. Bacteria able to replicate within macrophages where those that presented a ratio $\geq 200 \%$. Adherent/invasive bacteria able to survive and to multiply within macrophage were considered AIEC strains. All assays were performed in three independent experiments, in duplicate.

\section{PFGE with Xbal-digested genomic DNA}

The genetic relationship among AIEC isolates was examined by pulse-field electrophoresis (PFGE). Briefly, bacterial cultures were suspended in TN-buffer (Tris- $\mathrm{HCl}$ $50 \mathrm{mM} \mathrm{pH} \mathrm{7.4,} \mathrm{NaCl} 150 \mathrm{mM}$ ) and embedded in $1 \%$ agarose (LM-MP agarose, Roche, Italy) plugs. Embedded bacteria were lysed by immerging the plugs in a solution of Tris- $\mathrm{HCl} 200 \mathrm{mM} \mathrm{pH} 7.4$, EDTA $0.5 \mathrm{M} \mathrm{pH} \mathrm{8,} \mathrm{SDS}$ $10 \%$ proteinase $\mathrm{K}(20 \mathrm{mg} / \mathrm{ml}$, Roche $)$ and incubated for $24 \mathrm{~h}$ at $56^{\circ} \mathrm{C}$. Agarose plugs were washed once with TEbuffer (Tris- $\mathrm{HCl} 200 \mathrm{mM}$ pH 7.4, EDTA $0.5 \mathrm{M} \mathrm{pH} \mathrm{8)}$ and DNA was digested with $40 \mathrm{U} /$ plug of $\mathrm{XbaI}$ overnight at $37^{\circ} \mathrm{C}$. The restriction fragments were separated by PFGE on a CHEF-DR II system (Bio-Rad Laboratories, Richmond, CA, USA). The pulse time ranged from 1 to 20 seconds over 21 hours $(6 \mathrm{~V} / \mathrm{cm})$ at $14^{\circ} \mathrm{C}$. Lambda concatemers (New England Biolabs, Ipswich, MA) were used as size standard. Gels were stained with ethidium bromide and digitalized using the Kodak Digital Science system (Kodak, Milan, Italy).

\section{PCR-based fingerprinting using random amplified polymorphic DNA (RAPD)}

Genotyping of AIEC isolates was performed using RAPD PCR. Bacterial DNA was purified using mericon DNA Bacteria Kit (Qiagen, Italy) according to the manufacturer's instructions. RAPD reactions were performed using two arbitrary primers; primer 3 (5'-d[GTAGACCCGT]-3') and primer 4 (5'-d[AAGAGCCCGT]-3') [30]. Each lyophilized primer was rehydrated in sterile distilled water prior to use. Amplification was performed in a $25-\mu \mathrm{L}$ reaction mixture containing $1.5 \mathrm{mM} \mathrm{MgCl}_{2}$ (Bioline, London, $\mathrm{UK}$ ), $0.2 \mathrm{mM}$ dNTPs (Promega, Madison, WI, USA), $0.5 \mu \mathrm{M}$ of each primer, $1 \mathrm{U}$ BioTaq $^{\mathrm{Tm}}$ of DNA polymerase in $1 \mathrm{X}$ PCR buffer (Bioline, London, UK) and $3 \mu \mathrm{L}$ of template dsDNA (40 ng). PCR was performed as follows: 1 cycle at $95^{\circ} \mathrm{C}$ for $5 \mathrm{~min}$, followed by 45 cycles at $95^{\circ} \mathrm{C}$ for $1 \mathrm{~min}, 36^{\circ} \mathrm{C}$ for $1 \mathrm{~min}$, and $72^{\circ} \mathrm{C}$ for $2 \mathrm{~min}$ (Mastercycler pro, Eppendorf Germany). Ten microliters of all reactions were electrophoresed in $2.0 \%$ agarose gels, stained with ethidium bromide and photographed by use a ultraviolet transilluminator and a digital capture system (UVP Inc.) In order to guarantee reproducibility of RAPD profiles, each PCR reaction was performed in triplicate.

\section{PFGE and RAPD profiles analysis}

The DNA banding patterns obtained by PFGE and RAPD assays were analysed with TotalLab TL120 Trace version 2006 (Nonlinear Dynamics) with a position tolerance set at $1,5 \%$. The Dice coefficient of similarity was calculated, and the unweighted pair group method with arithmetic averages (UPGMA) was used for cluster analysis XLstat 7.5 (Addinsoft, USA). The similarity percentage cut-off to distinguish between clonally distinct groups was set at $95 \%$.

\section{Adhesion phenotypes assay}

The pattern of adhesiveness of our AIEC-like strains was evaluated using HEp-2 and Caco- 2 cell monolayers, localized adherence (LA), diffuse adherence (DA) and enteroadherentaggregative adherence (AA) were determined for all the AIEC genotypes by the method described by Scaletsky et al. [31]. Monolayers were infected with bacterial suspensions $\left(10^{6}\right.$ bacteria $\left./ \mathrm{ml} ; \mathrm{MOI}=10\right)$ and incubated at $37^{\circ} \mathrm{C}$ for $3 \mathrm{~h}$. Infected monolayers were examined at light microscope after a 3 - $\mathrm{h}$ incubation period. When needed, bacterial cultures were harvested in the exponential phase and suspended in culture medium with and without $0.5 \%$ (wt/vol) D-mannose (Sigma-Aldrich, Italy).

\section{Phylotyping}

The phylogenetic group of all E. coli AIEC genotypes was assayed by a multiplex PCR protocol [32]. The oligonucleotide primers were designed to amplify the $E$. coli associated genes chuA, yjaA and TspE4C2. Phylogenetic clustering was made on the basis of the results of amplification. Namely group A was $c h u A-$, yjaA +/-, TspE4C2-, group B1 chuA-, yjaA+/-, TspE4C2+, group $\mathrm{B} 2 \mathrm{chuA+,} y j a A+$, TspE4C2+/-, group D chuA+, yjaA-, TspE4C2+/-. Amplifications were carried out in $25 \mu \mathrm{l}$ reaction mixtures composed of $1 \mathrm{X}$ PCR reaction buffer (Biolabs Inc.), $50 \mathrm{ng} / \mu \mathrm{l}$ of template DNA, $0.2 \mathrm{mM}$ of dNTPs (Biolabs Inc.), $0.5 \mu \mathrm{M}$ of primers (Sigma), $1.25 \mathrm{U}$ Taq DNA polymerase (Biolabs Inc.). Amplification was carried out for 30 cycles each consisting of a denaturing step of $5 \mathrm{~min}$ at $95^{\circ} \mathrm{C}$, followed by an annealing step of $30 \mathrm{~s}$ at $56^{\circ} \mathrm{C}$ and an extension step of $5 \mathrm{~min}$ at $72^{\circ} \mathrm{C}$. The amplification products were separated by electrophoresis in $2.0 \%$ agarose gels, in $45 \mathrm{mM}$ Tris-borate, $1 \mathrm{mM}$ EDTA buffer $(\mathrm{pH}=8.0)$ containing ethidium bromide at $0.5 \mu \mathrm{g} / \mathrm{ml}$ at a constant voltage of $5 \mathrm{~V} / \mathrm{cm}$. Gels were photographed under transillumination using a digital camera (UVP Inc.) Amplification was performed in triplicate. The size of amplicons was determined by comparison with a 100-bp DNA ladder (Biolabs inc.).

\section{Virulence genotyping by PCR}

All the AIEC genotypes were assayed for selected virulence and fimbrial adhesin genes known to be associated 
with virulent $E$. coli strains by multiplex PCR using appropriate primers [see Table 1]. Whole DNA bacterial extracts were prepared using Qiagen DNA extraction kit (Qiagen, Italy). E. coli strains known to encode the assayed virulence traits were included as controls. Amplifications were carried out for 30 cycles in $25 \mu \mathrm{l}$ in $1 \mathrm{X}$ reaction buffer (Euroclone). Each reaction mixture contained $50 \mathrm{ng} / \mu \mathrm{l}$ of each of template DNA, $1.5 \mathrm{mM}$ $\mathrm{MgCl}_{2}, 0.2 \mathrm{mM}$ of dNTPs (Biolabs Inc.), $0.5 \mu \mathrm{M}$ of each primer pairs, $1.25 \mathrm{U}$ of Taq DNA polymerase (Euroclone). For some virulence genes, namely gafD, cvaC, focG, traT and papG allele II; sfa/focDE, iutA, papG allele III) the multiplex PCR amplification was carried out in a total volume of $50 \mu \mathrm{l}$, using $5 \mu \mathrm{l}$ of whole bacterial DNA extracts as templates. The amplification products were separated by electrophoresis in $2.0 \%$ agarose gels, as described above and stained with ethidium bromide. Gels were photographed using a digital camera (UVP Inc.) Amplification was performed in triplicate. The size of amplicons was determined by comparison with a 100-bp DNA ladder (Biolabs Inc.).

\section{Statistical methods}

The differences in the distribution of phylogroups of AIEC strains, between the two populations of subjects studied, were calculated using the $\chi^{2}$ test with Yates' continuity correction. For Dice similarity index a bilateral Mann-Whitney $U$-test was utilized to compare patients and controls. In both cases, a $P$ value $\leq 0.05$ was considered statistically significant.

\section{Results}

High abundance of adherent $E$. coli isolates from CD patients

Six-hundred sixteen independent E. coli isolates were collected from ileal mucosa biopsies from four pediatric $\mathrm{CD}$ patients and from four non-IBD controls. Isolates were assayed for their ability to adhere to HEp-2 and Caco-2 cell monolayers (as described in Materials and Methods) and a total of 226 adherent E. coli isolates were detected. The relative abundance of adhesive isolates was significantly higher among isolates from $C D$ patients than non-IBD controls: $63 \%(161 / 255)$ vs $23 \%$ (65/273) $(\chi 2=81.69 P<0.001)$, respectively. We could not determine the adhesive ability of 88 isolates (53 E. coli isolates from CD patients, and of 35 from non-IBD controls) since they were highly cytotoxic when challenged with tissue culture (detachment and lysis of cell monolayers was observed $3 \mathrm{~h}$ post infection) (data not shown). Analysis of these 88 isolates revealed that all produced higher levels of hemolysin, and the release of hemolysin may likely account for the high cytotoxic activity of these isolates [34]. These strains were not used for further analysis.

\section{Invasive $E$. coli isolates were able to replicate within macrophages}

Invasiveness of the 226 adherent $E$. coli isolates was tested by the gentamicin protection assay using HEp-2 cell monolayers [13]. At the end of the gentamicin treatment, infected cell monolayers were extensively washed, lysed, and the number of intracellular bacteria determined for each isolate (see Materials and methods for details). Isolates were considered invasive when the CFUs of each invasive bacteria was superior or equal to $0.1 \%$ of the number of bacteria used to infect cell monolayers $(\mathrm{MOI}=10)$. Reference $E$. coli $\mathrm{K}-12$ strain DH5 $\alpha$ and reference AIEC strain LF82 were used an non-invasive and invasive controls, respectively. Under our experimental conditions DH5 $\alpha$ presented an invasive score of $0.0007 \% \pm 0.0005$ while LF82 a score of $0.95 \% \pm 0.3$ in respect of the initial bacterial inoculum (Table 2). Of the 226 adhesive isolates, 36 were also invasive (invasive score ranged from $0.40 \% \pm 0.11 \%$ to $0.88 \% \pm 0.27 \%$ ) and of these 31 isolates were from three of the four $\mathrm{CD}$ patients and 5 from two of the four non-IBD controls. The relative abundance (\% AIEC isolates/total E. coli isolates) was significantly higher among isolates from $C D$ patients $(31 / 308 ; 10.06 \%)$ than in nonIBD controls $(5 / 308 ; 1.62 \%)(\chi 2=18.43 \mathrm{p}<0.0001)$. Furthermore, the relative abundance (\% AIEC isolates/total $E$. coli isolates for each patient) was $14 / 77(18,18 \%), 9 / 77$ (11,68\%), 8/77 (10,38\%), 0/77 (0\%) in CD1,CD2,CD3 and $\mathrm{CD} 4$ respectively (mean $\pm \mathrm{SD} ; 10,06 \pm 7,52$ ) and $4 / 77$ (5,19\%), 1/77 (1,29\%), 0/77 (0\%), 0/77 (0\%) in controls $1,2,3$ and 4 respectively (mean \pm SD; $1,62 \pm 2,45$ ).

To assess whether the 36 adhesive-invasive isolates were putative AIEC-like isolates, they were further assayed for the ability to survive and multiply within macrophages. The number of bacteria surviving the gentamicin treatment was evaluated at 1 and $24 \mathrm{~h}$ post-infection. As expected, when challenged with 7774 macrophages, the non-invasive K-12 DH5 $\alpha$ strain was rapidly eliminated, while LF82 retained its ability to survive and multiply within macrophages. Remarkably, all the 36 adherent-invasive $E$. coli isolates, were able to survive and multiply within J774 macrophages (Table 3). This finding clearly indicated that they may well be considered AIEC-like isolates [17].

\section{Genotypic variants among AIEC isolates}

PFGE and RAPD fingerprinting analysis was conducted in order to genotypically characterize the 36 AIEC-like isolates and a dendrogram was constructed (Figure 1). Using this approach, we detected 27 different genotypes among the 36 AIEC-like isolates (22 were from CD patients and 5 from non-IBD controls). Genotypes belonging to the same patient tended to cluster. Six to 10 genetic variants (mean $\pm \mathrm{SD}$; $7.3 \% \pm 2.3 \%$ ) were detected among the 22 AIEC-like strains isolated from $\mathrm{CD}$ 
Table 1 Primers used for PCR analysis of known virulence genes of extra-intestinal pathogenic $E$. coli

\begin{tabular}{|c|c|c|c|c|}
\hline Virulence traits & Genes & Primer sequence (5'à 3') & Expected amplicon size (bp) & References \\
\hline \multirow{4}{*}{ P fimbriae } & \multirow{2}{*}{ papA } & ATGGCAGTGGTGTCTITTGGTG & \multirow{2}{*}{720} & \multirow{2}{*}[33]{} \\
\hline & & CGTCCCACCATACGTGCTCTTC & & \\
\hline & \multirow{2}{*}{ papEF } & GCAACAGCAACGCTGGTTGCATCAT & \multirow{2}{*}{336} & \multirow{2}{*}{ [33] } \\
\hline & & AGAGAGAGCCACTCTTATACGGACA & & \\
\hline \multirow{4}{*}{ P pili-associated G-adhesins } & \multirow{2}{*}{ papC } & GACGGCTGTACTGCAGGGTGTGGCG & \multirow{2}{*}{328} & \multirow{2}{*}{ [33] } \\
\hline & & ATATCCTITCTGCAGGGATGCAATA & & \\
\hline & \multirow{2}{*}{ papG allele II e III } & CTGTAATTACGGAAGTGATTTCTG & \multirow{2}{*}{1070} & \multirow{2}{*}{ [33] } \\
\hline & & ACTATCCGGCTCCGGATAAACCAT & & \\
\hline \multirow{4}{*}{ Pyelonephritis-associated pili } & \multirow{2}{*}{ papG allele II } & GGGATGAGCGGGCCTTTGAT & \multirow{2}{*}{190} & \multirow{2}{*}{ [33] } \\
\hline & & CGGGCCCCCAAGTAACTCG & & \\
\hline & \multirow{2}{*}{ papG allele III } & GGCCTGCAATGGATTTACCTGG & \multirow{2}{*}{258} & \multirow{2}{*}{ [33] } \\
\hline & & CCACCAAATGACCATGCCAGAC & & \\
\hline \multirow{2}{*}{$\mathrm{S}$ and F1C fimbriae } & \multirow{2}{*}{$s f a / / f o c D E$} & CTCCGGAGAACTGGGTGCATCTTAC & \multirow{2}{*}{410} & \\
\hline & & CGGAGGAGTAATTACAAACCTGGCA & & [33] \\
\hline F1C fimbriae & $f \cap c G$ & CAGCACAGGCAGTGGATACGA & & \\
\hline ric immondae & $100 \mathrm{C}$ & GAATGTCGCCTGCCCATTGCT & 360 & [33] \\
\hline Dr-binding adhesin & $a f a l d r a R r$ & GGCAGAGGGCCGGCAACAGGC & & {$[32]$} \\
\hline Di-binuming damesin & arararabe & CCCGTAACGCGCCAGCATCTC & 339 & {$[35]$} \\
\hline fimbrias & Paf & TGTTGGACCGTCTCAGGGCTC & 052 & {$[32]$} \\
\hline Uimonide & gain & CTCCCGGAACTCGCTGTTACT & 902 & ] \\
\hline Nonfimbrial adhesin tyne 1 & $n f_{0} F_{0}$ & GCTTACTGATTCTGGGATGGA & 550 & 5237 \\
\hline (2010 & & CGGTGGCCGAGTCATATGCCA & 559 & {$[33]$} \\
\hline Mannose-specific adhesion gene. & $f i m H$ & TGCAGAACGGATAAGCCGTGG & 508 & {$[22]$} \\
\hline Type1 fimbriae. & (IIIா & GCAGTCACCTGCCCTCCGGTA & 500 & {$[3]$} \\
\hline Haemolysin A & hlva & AACAAGGATAAGCACTGTTCTGGCT & 1177 & {$[33]$} \\
\hline ה & myn & ACCATATAAGCGGTCATTCCCGTCA & (11/1 & {$[3]$} \\
\hline Cytotoxic necrotizing factor 1 & $\operatorname{snf1}$ & GTGATAATATATCACATTATTC & 198 & {$[32]$} \\
\hline 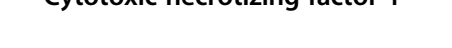 & (7III) & GAATTCGTCTCGTTGAGCTTCACTG & 470 & 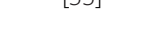 \\
\hline Yersiniabactin sideronhore recentor & $f(u A$ & TGATTAACCCCGCGACGGGAA & 880 & {$[327$} \\
\hline & 进 & CGCAGTAGGCACGATGTTGTA & 000 & [J] \\
\hline Aerobactin siderophore receptor & iute & GGCTGGACATCATGGGAACTGG & 300 & 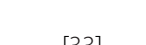 \\
\hline Aerobactin sideropnore receptor & IUtA & CGTCGGGAACGGGTAGAATCG & 500 & {$[33]$} \\
\hline & KnSMT $\|$ & GCGCATTTGCTGATACTGTTG & 272 & {$[237$} \\
\hline & & CATCCAGACGATAAGCATGAGCA & & {$[3]$} \\
\hline & kDsMTIII & TCCTCTTGCTACTATTCCCCCT & 392 & [33] \\
\hline Cansule synthesis nrimers & & AGGCGTATCCATCCCTCCTAAC & 型 & \\
\hline - & knsMAT1 $(K$ & TAGCAAACGTTCTATTGGTGC & 153 & {$[32]$} \\
\hline & 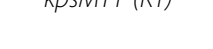 & CATCCAGACGATAAGCATGAGCA & 153 & {$[33]$} \\
\hline & KnSMUT 5 (K5) & CAGTATCAGCAATCGTTCTGTA & $150 \times 0$ & {$[23]$} \\
\hline & 年 & CATCCAGACGATAAGCATGAGCA & 159 & 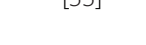 \\
\hline Invasion of brain endothelium gene & thet & AGGCAGGTGTGCGCCGCGTAC & 170 & 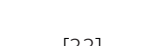 \\
\hline (associate with neonatal meningitis) & 10EA & TGGTGCTCCGGCAAACCATGC & $1 / 0$ & {$[33]$} \\
\hline Encodes colicin V & cyoc & CACACACAAACGGGAGCTGTT & 6 & $F=$ \\
\hline & & CTTCCCGCAGCATAGTTCCAT & 080 & {$[35]$} \\
\hline
\end{tabular}


Table 1 Primers used for PCR analysis of known virulence genes of extra-intestinal pathogenic E. coli (Continued)

\begin{tabular}{|c|c|c|c|c|}
\hline \multirow{2}{*}{ Serum resistance gene } & \multirow{2}{*}{ trat } & GGTGTGGTGCGATGAGCACAG & \multirow{2}{*}{290} & \multirow{2}{*}{33} \\
\hline & & CACGGTTCAGCCATCCCTGAG & & \\
\hline \multirow{2}{*}{$\begin{array}{l}\text { Pathogenicity islands described in a } \\
\text { virulent uropathogen. }\end{array}$} & \multirow{2}{*}{ PAl } & GGACATCCTGTTACAGCGCGCA & \multirow{2}{*}{930} & \multirow{2}{*}{ [33] } \\
\hline & & TCGCCACCAATCACAGCCGAAC & & \\
\hline \multirow{2}{*}{$\begin{array}{l}\text { Transcriptional Activator gene of } \\
\text { aggregative adhesion fimbriae }\end{array}$} & \multirow{2}{*}{$\operatorname{agg} R$} & GTATACACAAAAGAAGGAAGC & \multirow{2}{*}{254} & \multirow{2}{*}[34]{} \\
\hline & & ACAGAATCGTCAGCATCAGC & & \\
\hline \multirow{2}{*}{$\begin{array}{l}\text { CVD432 gene probe sequence of the } \\
\text { plasmid of aggregative adhesion }\end{array}$} & \multirow{2}{*}{ pAA (CVD432) } & CTGGCCAAAGACTGTATCAT & \multirow{2}{*}{630} & \multirow{2}{*}{ [34] } \\
\hline & & CAATGTATAGAAATCCGCTGTT & & \\
\hline
\end{tabular}

patients, while 1 to 4 (mean \pm SD: $2.5 \pm 2.1$ ) were obtained from AIEC-like strains isolated from non-IBD controls. Although the differences in genotypic richness are not statistically significant, because of the small number of patients enrolled in this study, these results may suggest a higher diversity among AIEC strains isolated from CD patients compared to those isolated from non-IBD controls. The similarity level among the 27 genotypes, computed by calculating the Dice index, showed a statistically significant difference $(P<0.0001)$ between intra-individual similarity $(88.9 \% \pm 8.9 \%)$ and inter-individual similarity $(52.1 \% \pm 8.0 \%)$ (Figure 2$)$. Due to the small number of patients enrolled in this study these differences cannot be considered significant although they are in agreement with previous findings suggesting a higher diversity among AIEC strains isolated from CD patients. Further study is surely needed to clarify this point.

All the AIEC-like strains show an aggregative (AA) pattern of adherence

The pattern of adherence of the 27 AIEC-like strains was determined using HEp-2 as well as Caco-2 cell

Table 2 HEp-2 invasiveness of the 36 AIEC isolated from patients with CD (CD1-4) and from non-IBD controls (Control 1-4)

\begin{tabular}{lcc}
\hline Sample origin & N of invasive strains & ${ }^{\mathbf{a}}(\%)$ Average invasion level \\
\hline CD1 & 14 & $0.50 \pm 0.15$ \\
CD2 & 9 & $0.40 \pm 0.11$ \\
CD3 & 8 & $0.88 \pm 0.27$ \\
CD4 & 0 & -- \\
Control 1 & 4 & $0.67 \pm 0.10$ \\
Control 2 & 1 & $0.52 \pm 0.15$ \\
Control 3 & 0 & -- \\
Control 4 & 0 & -- \\
Reference strains & E. coli LF82 & $0.95 \pm 0.30$ \\
& E. coli DH5a & $0.007 \pm 0.005$
\end{tabular}

${ }^{a}$ Values represent the mean percentages \pm standard deviations of the means of internalised bacteria and are expressed as the ratio of intracellular CFU/number of bacteria used to infect cell monolayers X 100. Data represent mean and standard errors of three independent experiments, in duplicate.

-- , not determined. monolayers. Remarkably, as AIEC strain LF82, all the 27 AIEC-like strains presented an aggregative pattern of adherence (AA) (Figure 3) that was inhibited by co-culturing bacteria and both type of epithelial cells with D-mannose (data not shown). These data are in agreement with previous work indicating that expression of type 1 pili is necessary for AIEC adhesiveness [19,35].

Phylogenetic grouping and virulence genetic markers of the AIEC-like isolates

The phylogenetic background of the 27 AIEC genotypes was examined by PCR grouping analysis, as previously described [32]. The 22 AIEC-like genotypes isolated from $C D$ patients were phylogenetically classified as follows: $40.9 \%$ (9/22) belonged to group A, 31.8\% (7/22) belonged to group D, while only $18.2 \%(4 / 22)$ and $9.1 \%$ $(2 / 22)$ belonged to groups B1 and B2, respectively. Of the five AIEC strains isolated from the non-IBD controls, 80\% (4/5) belonged to group A and 20\% (1/5) to group B2. Although it has previously reported that the B2 and D phylogroups were the most prevalent among AIEC isolates [16,36], our result did not show significant differences in phylogroup predominance and in phylogroups distribution in IBD compared to controls. With the exception of $\mathrm{fimH}$ that was detected in all the 27 AIEC genotypes, significant differences in the presence

Table 3 Thirty-six adherent/invasive $E$. coli isolates were able to persist and to replicate within $\mathbf{J 7 7 4}$ macrophages

\begin{tabular}{lcc}
\hline Sample origin & N of isolates & $\begin{array}{c}\text { apercentage of survival/replication } \\
\text { in J744 macrophages }\end{array}$ \\
\hline CD1 & 14 & $403 \pm 102$ \\
CD2 & 9 & $638 \pm 113$ \\
CD3 & 8 & $417 \pm 133$ \\
Control 1 & 4 & $376 \pm 67$ \\
Control 2 & 1 & $340 \pm 110$ \\
Controls strains & E. coli LF82 & $580 \pm 120$ \\
& E. coli DH5a & $7.3 \pm 4.0$
\end{tabular}

aPercentage of intracellular bacteria at 24 hours post infection relative to the number of bacteria after $1 \mathrm{~h}$ of gentamicin treatment, defined as $100 \%$. CD1-3, CD patients; Control 1-2; non-IBD patients. Data represent mean and standard errors of three independent experiments made in duplicate. 


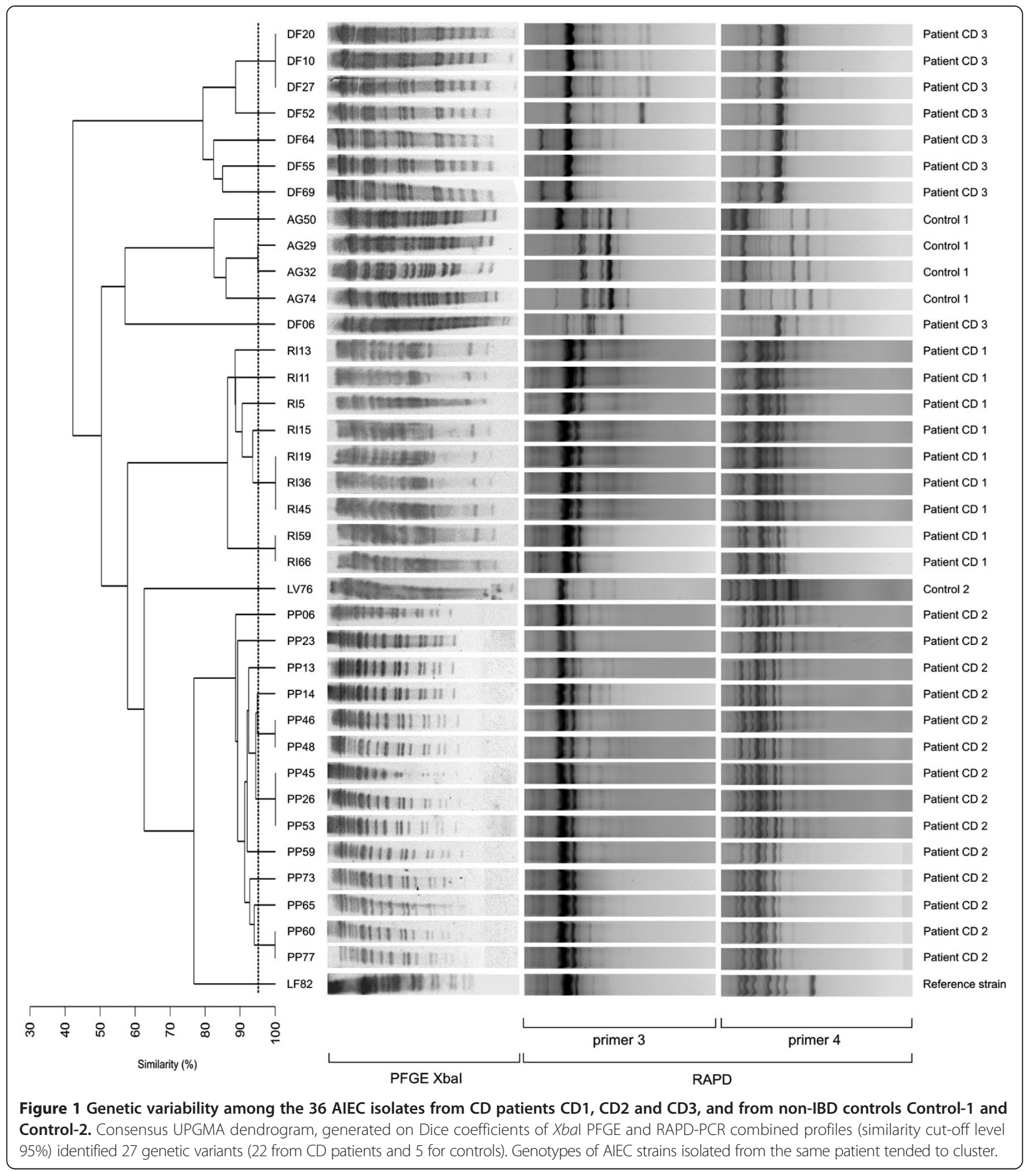

of virulence gene were found between the AIEC genotypes isolated from CD patients and the non-IBD controls (Table 4). Furthermore we found that virulence gene profiles were more similar in genotypes coming from the same patient being the intra-individual similarity $(89,3 \% \pm 12,2 \%)$ statistically different from. interindividual one $(53,0 \% \pm 28,1 \%)(\mathrm{p}<0,0001)$.

\section{Discussion}

In this work, a large number of $E$. coli isolates obtained from ileal mucosa biopsies from four pediatric $C D$ patients and from four non-IBD controls (77 isolates per biopsy, for a total of 616 independent isolates) were characterized. Isolates were analyzed to evaluate the presence and the abundance of AIEC strains. The ability 


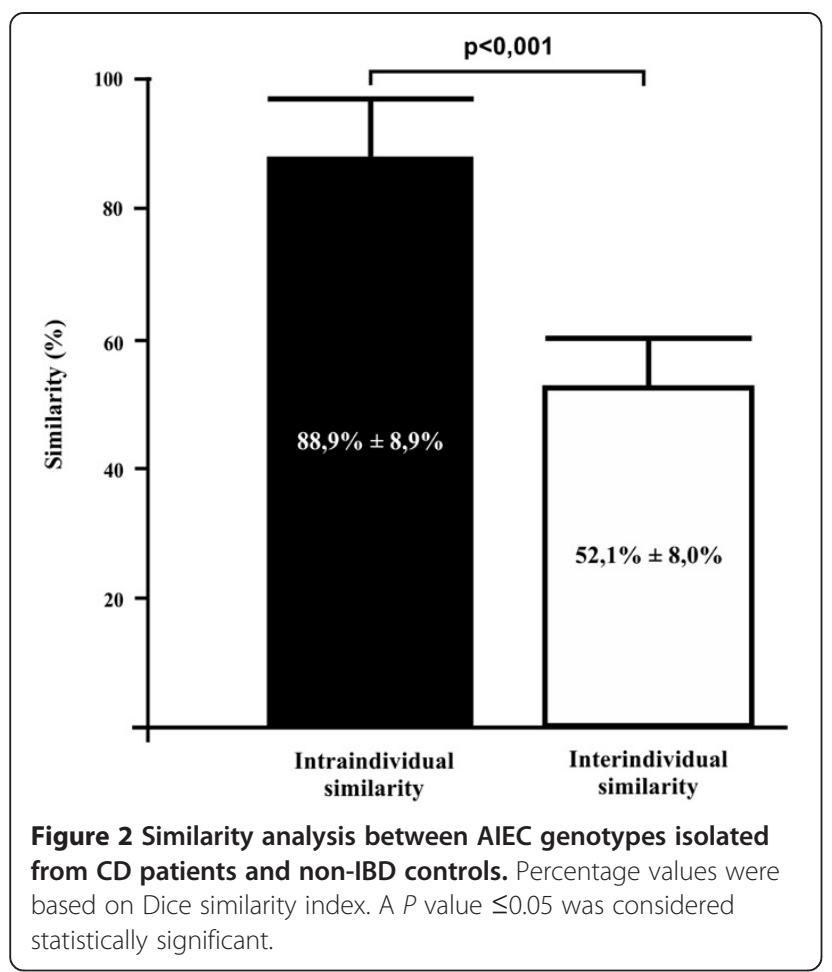

to adhere, to invade HEp-2 cell monolayers and to survive and multiply within macrophages (typical AIEC characteristics) were detected for $36 \mathrm{E}$. coli isolates (AIEC-like strains). We noticed a significant higher relative abundance of AIEC-like isolates among biopsies of CD patients (31 isolates vs five isolates from non-IBD controls), supporting previous findings indicating a close association of AIEC strains with CD patients intestinal mucosa [16,37]. Combined RAPD and PFGE fingerprints analysis, conducted on the 36 AIEC-like isolates, evidenced 27 different genotypes, each of which appeared to be unique for each patient. Indeed, patient CD1 harboured up to 10 distinct AIEC genotypes while patients $\mathrm{CD} 2$ and $\mathrm{CD} 3$ both harboured 6 distinct genotypes, while four and one distinct genotypes were found for AIEC strains isolated from Control 1 and 2, respectively. Furthermore, the dendogram, shown in Figure 1, also indicates that AIEC strains isolated from the same patients are closely related. Alike reference AIEC LF82 strain, all the 27 AIEC genotypes presented an AA pattern of adherence on HEp- 2 cells. This result, led us to speculate that this pattern could favor the intestinal colonization and persistence within the inflamed intestinal mucosa of $\mathrm{CD}$, at least in pediatric $\mathrm{CD}$ patients $[16,34]$.

In contrast with studies regarding adult $\mathrm{CD}$ patients which reported phylogroup B2 as the predominant one [16], phylogroup B2 was not predominant among our

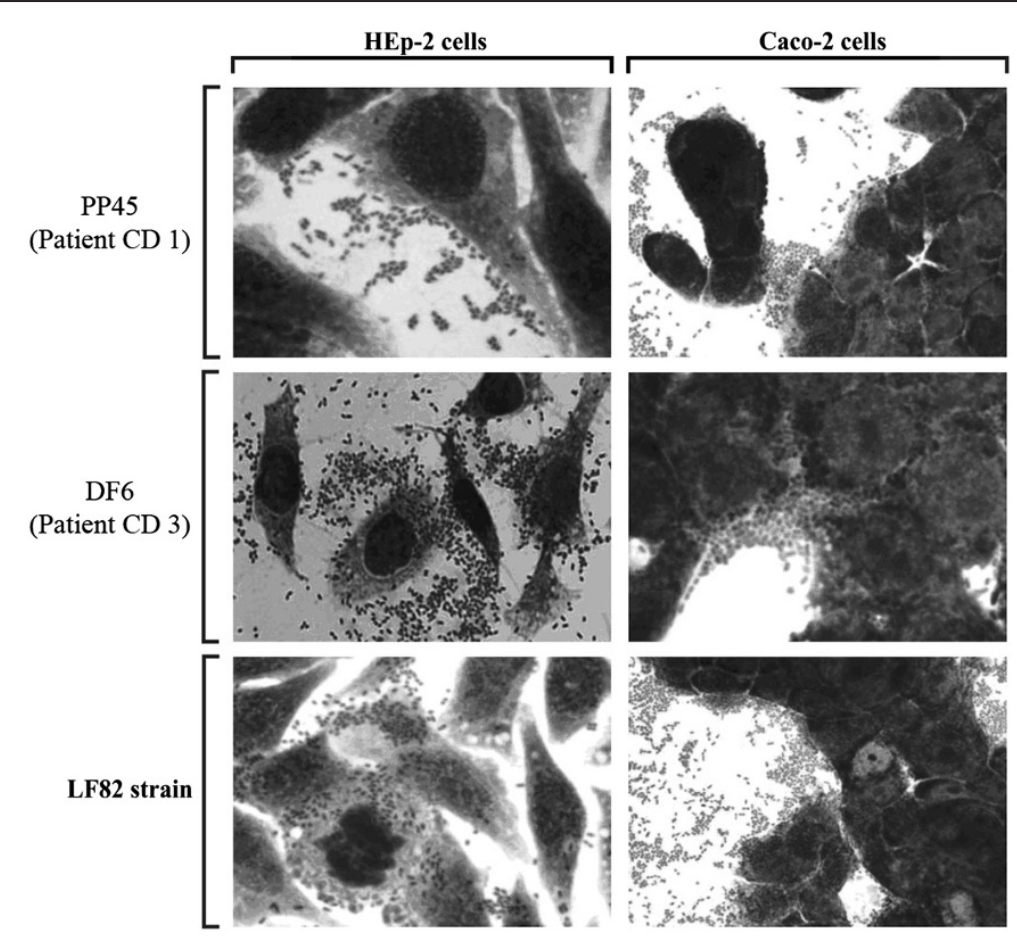

Figure 3 Adhesion phenotypes assay. Phase contrast fields showing Hep-2 and Caco-2 cell monolayers infected with two representative AlEC strains isolated in this work (PP45 and DF6) and with reference AIEC LF82 strain. All 27 AIEC strains showed an aggregative (AA) patterns of adherence. Magnification, $1000 \mathrm{X}$. 
Table 4 Prevalence of virulence genes, identified for each strain by PCR, in the 22 AIEC strains in CD and in the 5 non-IBD pediatric patients

\begin{tabular}{|c|c|c|c|c|}
\hline \multicolumn{2}{|l|}{ Virulence Factors } & \multirow{2}{*}{$\begin{array}{c}\begin{array}{c}\% \text { of virulence genes in AIEC isolates } \\
\text { from CD patients }(\mathbf{n}=\mathbf{2 2})\end{array} \\
0,00 \%\end{array}$} & \multirow{2}{*}{$\begin{array}{c}\begin{array}{l}\% \text { of virulence genes in } \\
\text { non-IBD controls }(\mathbf{n}=\mathbf{5})\end{array} \\
0,00 \%\end{array}$} & \multirow{2}{*}{$\begin{array}{c}{ }^{\text {ap value }} \\
-\end{array}$} \\
\hline Adhesins & papA & & & \\
\hline & papC & $0,00 \%$ & $0,00 \%$ & -- \\
\hline & papEF & $0,00 \%$ & $0,00 \%$ & -- \\
\hline & papG & $0,00 \%$ & $0,00 \%$ & -- \\
\hline & papG allele II & $13.63 \%$ & $0,00 \%$ & NS \\
\hline & papG allele III & $0,00 \%$ & $0,00 \%$ & -- \\
\hline & papG allele II e III & $0,00 \%$ & $0,00 \%$ & -- \\
\hline & $s f a / f o c D E$ & $0,00 \%$ & $0,00 \%$ & -- \\
\hline & focG & $0,00 \%$ & $0,00 \%$ & -- \\
\hline & $\operatorname{fimH}$ & $100.00 \%$ & $100.00 \%$ & NS \\
\hline & Afa/DraBC, & $0,00 \%$ & $0,00 \%$ & -- \\
\hline & $n f a \mathrm{E}$ & $0,00 \%$ & $0,00 \%$ & -- \\
\hline & gafD & $0,00 \%$ & $0,00 \%$ & -- \\
\hline \multirow[t]{5}{*}{ Capsule } & $K 1$ & $72.72 \%$ & $0,00 \%$ & 0.013 \\
\hline & K5 & $4.54 \%$ & $0,00 \%$ & NS \\
\hline & kpsMT ॥ & $72.72 \%$ & $0,00 \%$ & 0.013 \\
\hline & kpsMT III & $0,00 \%$ & $0,00 \%$ & -- \\
\hline & $r f c$ & $0,00 \%$ & $0,00 \%$ & -- \\
\hline \multirow[t]{2}{*}{ Siderophores } & fyuA & $72.72 \%$ & $0,00 \%$ & 0.013 \\
\hline & iutA & $0,00 \%$ & $0,00 \%$ & -- \\
\hline \multirow[t]{3}{*}{ Toxins } & cnf1 & $0,00 \%$ & $0,00 \%$ & -- \\
\hline & crac & $0,00 \%$ & $0,00 \%$ & -- \\
\hline & hlyA & $0,00 \%$ & $0,00 \%$ & -- \\
\hline Invasin & ibeA & $81.81 \%$ & $0,00 \%$ & 0.001 \\
\hline Pathogenic island & $P A l$ & $0.00 \%$ & $0,00 \%$ & -- \\
\hline Resistance to serum & traT & $54.54 \%$ & $0,00 \%$ & NS \\
\hline $\begin{array}{l}\text { Transcriptional Activator gene of } \\
\text { aggregative adhesion fimbriae }\end{array}$ & $\operatorname{agg} R$ & $4,54 \%$ & $0,00 \%$ & NS \\
\hline $\begin{array}{l}\text { CVD432 gene probe sequence of the } \\
\text { plasmid of aggregative adhesion }\end{array}$ & pAA (CVD432) & $0,00 \%$ & $0,00 \%$ & -- \\
\hline
\end{tabular}

${ }^{\mathrm{a}} \mathrm{NS}$, not significative.

,-- not determined.

AIEC-like strains. Probably due to the small number of patients examined, we did not detect any significant phylogroup predominance or differences in phylogroup distribution. Nevertheless, we have previously reported [38] a very low proportion of B2 strains in AIEC strains of pediatric origin and isolated in Italy, suggesting that age and country of provenience may well be the cause of this discrepancy. With the exception of fimH, PCR-based identification of virulence genes known to be present in extra-intestinal pathogenic $E$. coli, indicated that only AIEC-like strains isolated from CD patients were positive for the presence of genes involved in the synthesis of capsular material $(K 1, K 5$ and kpsMT II), in the production of siderophores $(f y u A)$, invasiveness $(i b e A)$ and resistance to serum (traT). No CD-associated AIEC isolates was found positive for cnfl. Again, these results are in contrast with those reported by Martinez-Medina et al., [16] who found that the virulence gene content of mucosa-associated AIEC strains isolated from adult CD patients was similar to healthy controls. The finding that we detected virulence genes only in AIEC-like strains isolated from $\mathrm{CD}$ patients may be due to the small number of patients enrolled in this study or that by the use of pediatric patients. 


\section{Conclusions}

In conclusion, the AIEC-like abundance in CD patients and the presence of virulence genes only in CD patients further support the hypothesis that this pathovar may play an etiologic role in the insurgence and/or in the persistence in $C D$. These results are further supported by the recent findings indicating that colonization of the intestinal mucosa by AIEC strains, may initiate chronic inflammation of susceptible hosts by altering the gut microbiota [23]. Moreover, it has been recently reported a higher incidence of IBD in patients feed with fat-rich Western diet. It has been suggested that a fat-rich diet may induce changes in the composition of intestinal microbiota that, in turn, may influence the colonization and persistence of AIEC strains in genetically susceptible hosts [39]. These findings open up new scenarios addressed at the development of new strategies for the prevention and control of IBD not only based at eliminating AIEC strains from the inflamed intestinal mucosa but also throughout calibrated nutritional interventions.

\section{Competing interests}

The authors declare that they have no competing interests.

\section{Authors' contributions}

MPC and SS conceived and designed the experiments; MM ALC MA MSL VT performed the experiments; MPC SS ATP MM have been involved in data analysis; MPC CL MM ALC MA MSL CZ MN MA VT ATP SS contributed to reagents, materials and analysis tools. MPC and ATP contributed to drafting the manuscript. All authors read and approved the final manuscript.

\section{Acknowledgement \\ Supported by MIUR 2012 grants to MP. Conte.}

\section{Author details}

${ }^{1}$ Department of Public Health and Infectious Diseases, 'Sapienza' University of Rome, Rome, Italy. 'Departmen of Experimental and Clinical Sciences, University "G. D'Annunzio" Chieti, Chieti, Italy. ${ }^{3}$ Department of Pediatrics, University of Rome "La Sapienza", Rome, Italy. "Department of Public Health and Infectious Diseases, Pasteur Institute Cenci-Bolognetti Foundation, Sapienza University, Rome 00185, Italy. ${ }^{5}$ IRCCS San Raffaele Pisana, Rome 00166, Italy.

Received: 26 June 2014 Accepted: 14 October 2014

Published: 22 October 2014

\section{References}

1. Louis E, Collard A, Oger AF, Degroote E, Aboul Nasr El Yafi FA, Belaiche J: Behaviour of Crohn's disease according to the Vienna classification: changing pattern over the course of the disease. Gut 2001, 49:777-782.

2. Odze R: Diagnostic problems and advances in inflammatory bowel disease. Mod Pathol 2003, 16:347-358.

3. Xavier RJ, Podolsky DK: Unravelling the pathogenesis of inflammatory bowel disease. Nature 2007, 448:427-434.

4. Packey CD, Sartor RB: Interplay of commensal and pathogenic bacteria, genetic mutations, and immunoregulatory defects in the pathogenesis of inflammatory bowel diseases. J Intern Med 2008, 263:597-606.

5. Ley RE, Peterson DA, Gordon Jl: Ecological and Evolutionary Forces Shaping Microbial Diversity in the Human Intestine. Cell 2006, 124:837-848.

6. Walker AW, Sanderson JD, Churcher C, Parkes GC, Hudspith BN, Rayment N, Brostoff J, Parkhill J, Dougan G, Petrovska L: High-throughput clone library analysis of the mucosa-associated microbiota reveals dysbiosis and differences between inflamed and non-inflamed regions of the intestine in inflammatory bowel disease. BMC Microbiol 2011, 10:11-17.
7. Lepage $P$, Leclerc $M C$, Joossens $M$, Mondot $S$, Blottière HM, Raes J, Ehrlich D, Doré J: A metagenomic insight into our gut's microbiome. Gut 2013, 62:146-158.

8. Frank DN, St Amand AL, Feldman RA, Boedeker EC, Harpaz N, Pace NR: Molecular-phylogenetic characterization of microbial community imbalances in human inflammatory bowel diseases. PNAS 2007, 104:13780-13785.

9. Subramanian S, Campbell BJ, Rhodes JM: Bacteria in the pathogenesis of inflammatory bowel disease. Curr Opin Infect Dis 2006, 19:475-484.

10. Barnich N, Darfeuille-Michaud A: Role of bacteria in the etiopathogenesis of inflammatory bowel disease. World J Gastroenterol 2007, 13:5571-5576.

11. Masseret E, Boudeau J, Colombel JF, Neut C, Desreumaux P, Joly B, Corto A, Darfeuille-Michaud A: Genetically related Escherichia coli strains associated with Crohn's disease. Gut 2001, 48:320-325.

12. Boudeau J, Glasser AL, Masseret E, Joly B, Darfeuille-Michaud A: Invasive ability of an Escherichia coli strain isolated from the ileal mucosa of a patient with Crohn's disease. Infect Immun 1999, 67:4499-509.

13. Darfeuille-Michaud A, Boudeau J, Bulois P, Neut C, Glasser AL, Barnich N, Bringer MA, Swidsinski A, Beaugerie L, Colombel JF: High prevalence of adherent-invasive Escherichia coli associated with ileal mucosa in Crohn's disease. Gastroenterology 2004, 127:412-421.

14. Sasaki M, Sitaraman SV, Babbin BA, Gerner-Smidt P, Ribot EM, Garrett N, Alpern JA, Akyildiz A, Theiss AL, Nusrat A, Klapproth JM: Invasive Escherichia coli are a feature of Crohn's disease. Lab Invest 2007, 87:1042-1054.

15. Rolhion N, Darfeuille-Michaud A: Adherent-invasive Escherichia coli in inflammatory bowel disease. Inflamm Bowel Dis 2007, 13:1277-1283.

16. Martinez-Medina M, Aldeguer X, Lopez-Siles M, González-Huix F, López-Oliu C, Dahbi G, Blanco JE, Blanco J, Garcia-Gil LJ, Darfeuille-Michaud A: Molecular diversity of Escherichia coli in the human gut: new ecological evidence supporting the role of adherent-invasive E. coli (AIEC) in Crohn's disease. Inflamm Bowel Dis 2009, 15:872-878.

17. Glasser AL, Boudeau J, Barnich N, Perruchot MH, Colombel JF, DarfeuilleMichaud A: Adherent invasive Escherichia coli strains from patients with Crohn's disease survive and replicate within macrophages without inducing host cell death. Infect Immun 2001, 69:5529-5537.

18. Rolhion N, Barnich N, Claret L, Darfeuille-Michaud A: Strong decrease in invasive ability and outer membrane vesicle release in Crohn's disease-associated adherent-invasive Escherichia coli strain LF82 with the yfgL gene deleted. J Bacteriol 2005, 187:2286-2296.

19. Barnich N, Carvalho FA, Glasser AL, Darcha C, Jantscheff P, Allez M, Peeters H, Bommelaer G, Desreumaux P, Colombel JF, Darfeuille-Michaud A: CEACAM6 acts as a receptor for adherent-invasive $E$. coli, supporting ileal mucosa colonization in Crohn disease. J Clin Invest 2007, 117:1566-1574.

20. Rolhion N, Carvalho FA, Darfeuille-Michaud A: OmpC and the sigma(E) regulatory pathway are involved in adhesion and invasion of the Crohn's disease-associated Escherichia coli strain LF82. Mol Microbiol 2007, 63:1684-1700.

21. Wine E, Ossa JC, Gray-Owen SD, Sherman PM: Adherent-invasive Escherichia coli, strain LF82 disrupts apical junctional complexes in polarized epithelia. BMC Microbiol 2009, 9:180.

22. Eaves-Pyles T, Allen CA, Taormina J, Swidsinski A, Tutt CB, Jezek GE, Islas-Islas M, Torres AG: Escherichia coli isolated from a Crohn's disease patient adheres, invades, and induces inflammatory responses in polarized intestinal epithelial cells. Int J Med Microbiol 2008, 298:397-409.

23. Chassaing B, Rolhion N, de Vallée A, Salim SY, Prorok-Hamon M, Neut C, Campbell BJ, Söderholm JD, Hugot JP, Colombel JF, Darfeuille-Michaud A: Crohn disease-associated adherent-invasive $E$. coli bacteria target mouse and human Peyer's patches via long polar fimbriae. J Clin Invest 2011, 121:966-975.

24. Lapaquette P, Glasser AL, Huett A, Xavier RJ, Darfeuille-Michaud A: Crohn's disease-associated adherent-invasive $E$. coli are selectively favoured by impaired autophagy to replicate intracellularly. Cell Microbiol 2010, 12:99-113.

25. Miquel S, Peyretaillade $E_{1}$ Claret $L$, de Vallée A, Dossat $C$, Vacherie B, Zinebel H, Segurens B, Barbe V, Sauvanet P, Neut C, Colombel JF, Medigue C, Mojica FJ, Peyret $P$, Bonnet $R$, Darfeuille-Michaud A: Complete genome sequence of Crohn's disease-associated adherent-invasive E. coli strain LF82. PLoS One 2010, 5:e12714.

26. Chassaing B, Koren O, Carvalho FA, Ley RE, Gewirtz AT: AIEC pathobiont instigates chronic colitis in susceptible hosts by altering microbiota composition. Gut 2013, 63:1069-1080. 
27. Conte MP, Schippa S, Zamboni I, Penta M, Chiarini F, Seganti L, Osborn J, Falconieri P, Borrelli O, Cucchiara S: Gut-Associated bacterial microbiota in paediatric patients with inflammatory bowel disease. Gut 2006, 55:1760-1767

28. Nicoletti M, Superti F, Conti C, Calconi A, Zagaglia C: Virulence factors of lactose-negative Escherichia coli strains isolated from children with diarrhea in Somalia. J Clin Microbiol 1988, 26:524-529.

29. Bringer MA, Glasser AL, Tung CH, Méresse S, Darfeuille-Michaud A: The Crohn's disease-associated adherent-invasive Escherichia coli strain LF82 replicates in mature phagolysosomes within $\mathrm{J} 774$ macrophages. Cell Microbiol 2006, 8:471-484.

30. Radu S, Abdul Mutalib S, Rusul G, Ahmad Z, Morigaki T, Asai N, Kim YB, Okuda J, Nishibuchi M: Detection of Escherichia coli 0157:H7 in the beef marketed in Malaysia. Appl Environ Microbiol 1998, 64:1153-6.

31. Scaletsky IC, Silva ML, Trabulsi LR: Distinctive patterns of adherence of enteropathogenic Escherichia coli to HeLa cells. Infect Immun 1984, 45:534-536.

32. Clermont O, Bonacorsi S, Bingen E: Rapid and simple determination of the Escherichia coli phylogenetic group. Appl Environ Microbiol 2000, 66:4555-4558.

33. Johnson JR, Stell AL: Extended Virulence Genotypes of Escherichia coli strains from Patients with Urosepsis in Relation to Phylogeny and Host Compromise. J Infect Dis 2000, 181:261-72.

34. Thomazini CM, Samegima DA, Rodrigues MA, Victoria CR, Rodrigues J: High prevalence of aggregative adherent Escherichia coli strains in the mucosa-associated microbiota of patients with inflammatory bowel diseases. Int J Med Microbiol 2011, 301:475-479.

35. Moreira CG, Carneiro SM, Nataro JP, Trabulsi LR, Elias WP: Role of type I fimbriae in the aggregative adhesion pattern of enteroaggregative Escherichia coli. FEMS Microbiol Lett 2003, 226:79-85.

36. Petersen AM, Nielsen EM, Litrup E, Brynskov J, Mirsepasi H, Krogfelt KA: A phylogenetic group of Escherichia coli associated with active left-sided inflammatory bowel disease. BMC Microbiol 2009, 9:171.

37. De la Fuente M, Franchi L, Araya D, Díaz-Jiménez D, Olivares M, ÁlvarezLobos M, Golenbock D, González MJ, López-Kostner F, Quera R, Núñez G, Vidal R, Hermoso MA: Escherichia coli isolates from inflammatory bowel diseases patients survive in macrophages and activate NLRP3 inflammasome. Int J Med Microbiol 2014, 304:384-392.

38. Schippa S, Conte MP, Borrelli O, lebba V, Aleandri M, Seganti L, Longhi C, Chiarini F, Osborn J, Cucchiara S: Dominant genotypes in mucosaassociated Escherichia coli strains from pediatric patients with inflammatory bowel disease. Inflamm Bowel Dis 2009, 15:661-72.

39. Martinez-Medina M, Denizot J, Dreux N, Robin F, Billard E, Bonnet R, Darfeuille-Michaud A, Barnich N: Western diet induces dysbiosis with increased $E$. coli in CEABAC10 mice, alters host barrier function favouring AIEC colonization. Gut 2014, 63:116-124.

doi:10.1186/1756-0500-7-748

Cite this article as: Conte et al: Adherent-invasive Escherichia coli (AIEC) in pediatric Crohn's disease patients: phenotypic and genetic pathogenic features. BMC Research Notes 2014 7:748.

\section{Submit your next manuscript to BioMed Central and take full advantage of:}

- Convenient online submission

- Thorough peer review

- No space constraints or color figure charges

- Immediate publication on acceptance

- Inclusion in PubMed, CAS, Scopus and Google Scholar

- Research which is freely available for redistribution

Submit your manuscript at www.biomedcentral.com/submit
Ciomed Central 